\title{
Epiloia (Tuberous Sclerosis): A Report of a Case with Unusual Tumours
}

\author{
J. M. BERG, ELIZABETH A. GREEN, and M. A. C. RIDLER
}

From Cell Barnes and Harperbury Hospital Group, Harper Lane, near St Albans, Herts.

Apart from adenoma sebaceum, involvement of the skin and subcutaneous tissues is a well-known finding in cases of epiloia or tuberous sclerosis. A variety of manifestations occurs, the most frequently noted ones including adenoma sebaceum itself, shagreen plaques, subungual and other small fibromata, café-au-lait spots, and areas of depigmented skin. A comprehensive review of the dermatological aspects of the disease was published by Butterworth and Wilson (I94I) who summarized the many abnormalities that had been observed.

We recently saw a child in Cell Barnes hospital who, in addition to the typical clinical features of epiloia (in particular, epilepsy, mental defect, and adenoma sebaceum), developed superficial tumours which are sufficiently unusual to seem worth while reporting. The following is an account of this patient.

\section{Case Report}

A female child, the eldest in a sibship of three, was born on June 6,1958 to a mother of 28 years and a father of 33 years. A detailed review of the family history (grandparents, parents, sibs, uncles, aunts, and first cousins of the propositus) with the well-informed mother revealed no evidence of mental, neurological, or dermatological abnormalities, apart from the fact that the mother had a lipoma (about ro by $10 \mathrm{~cm}$.) situated on her back over the left lower ribs.

The pregnancy was normal until the last trimester when the mother developed toxaemia (hypertension and albuminuria), as a result of which a surgical induction was done at 36 weeks. This was followed by a vertex delivery of an infant, weighing $4 \mathrm{lb}$. I4 oz. (22IIg.), who appeared to be normal at birth and who progressed satisfactorily during the neonatal period.

In retrospect, the mother thought that the child had been rather slow in reaching her developmental milestones in the first 6 months of life, but, at the time, no abnormality was noted until generalized fits began at the age of 7 months. These first occurred on the day

Received June 23, 1965. when the second inoculation against poliomyelitis was given and they persisted to the present, despite the use of a variety of anticonvulsants (phenobarbitone, epanutin, phenytoin, and zarontin). Intervals between attacks varied from several hours to several months. An electroencephalogram, taken at the age of $2 \frac{1}{2}$ years, showed 'a definite abnormality with multifocal discharges suggesting the possibility of multiple, potentially epileptogenic lesions' (Dr. G. Pampiglione).

Mental subnormality became apparent by the age of about I year. The child first sat up at 13 months and began to walk at 20 months. At $3 \frac{1}{2}$ years, on the Vineland Social Maturity Scale, her social quotient was 40 and, at $5 \frac{1}{2}$ years, it was 30 . At the time of writing (aged 6 $\frac{1}{2}$ years), her vocabulary was limited to a few single words and an occasional short, simple phrase. She was unable to dress or undress herself, and she could not feed herself with a knife and fork. In addition, evidence of disturbed behaviour and withdrawal suggested the presence of psychosis to several observers.

The diagnosis of epiloia (tuberous sclerosis) was made with the development of facial adenoma sebaceum which was first suspected by the late Dr. D. H. H. Thomas, when the child was about 5 years old. At the age of $6 \frac{1}{2}$ years, these 'adenomata', on close inspection, were fairly distinct with a characteristic symmetrical distribution on both cheeks, mainly alongside the nose. They consisted of multiple nodules, most of them about a millimetre in diameter, with the colour of normal skin. Other cutaneous manifestations were an oval area of depigmented skin (about 4 by $2 \mathrm{~cm}$.) on the anterior aspect of the right thigh and a periungual fibroma (about the size of a pea) on the right little toe. Retinal phakomata were not detected on ophthalmoscopic examination. At 5 years, nodular areas of calcification in the paraventricular regions were noted on skull radiography, and an air encephalogram showed irregularity of the walls of the lateral ventricles with a wellmarked indentation in the region of the foramen of Munro. Intravenous pyelography and chest radiograph at that time revealed no abnormalities and there was no clinical evidence of renal, pulmonary, or cardiac disease. Measurements of the circumference, length, and breadth of the head at $6 \frac{1}{2}$ years $(53.1 \mathrm{~cm}$., $18.2 \mathrm{~cm}$., and $13.5 \mathrm{~cm}$., respectively) were within normal limits.

The unusual feature in this case was the development 


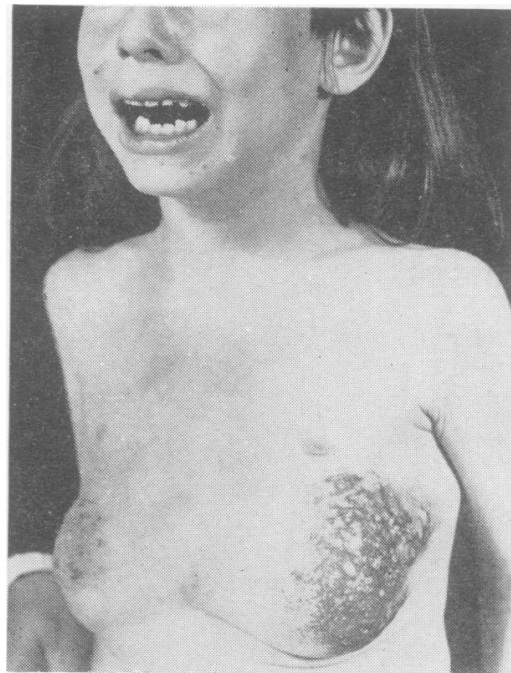

FIG. I. Tumours on chest wall in a 6-year-old girl with epiloia.

of bilateral tumours on the anterior chest wall (Fig. I). They were first observed by the mother at the age of about 9 months as two small patches of pigmented skin and grew rapidly to their present dimensions (right side-about the size of a man's fist; left side-about twice that size). The tumours were poorly circumscribed, of rubbery consistency, and mobile over the chest wall. The overlying skin was thickened, rough, darkly pigmented (Fig. 2), and hardly mobile over the masses. A small subcutaneous tumour (about 4 by $2 \mathrm{~cm}$.) of similar consistency to those on the chest, but without overlying skin involvement, was palpable on the right side of the abdomen. A biopsy specimen of the left chest tumour, taken at $2 \frac{1}{2}$ years, was examined microscopically by Dr. J. I. Pugh, who reported the

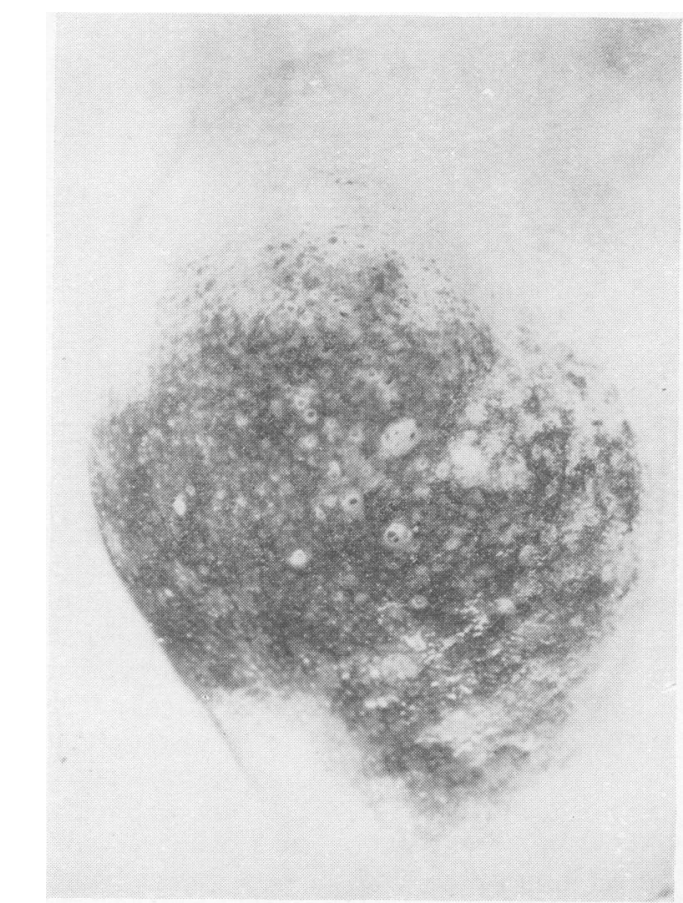

Fig. 2. Close-up view of tumour on left side of chest.

presence of 'a mass of mature collagenous fibrous tissuęำ arranged in interweaving bundles which blend with the fibrous tissue of the dermis and adipose tissue. Perio pheral nerve fibres are identified in the dermis but these do not seem abnormal. The appearances are those of fibrous hamartoma' (Fig. 3a). At $6 \frac{1}{4}$ years, a partia? excision of the right chest tumour was performed and this specimen was diagnosed on microscopical examina

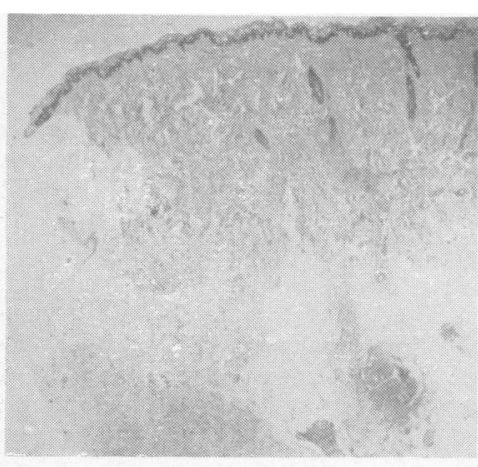

(a)

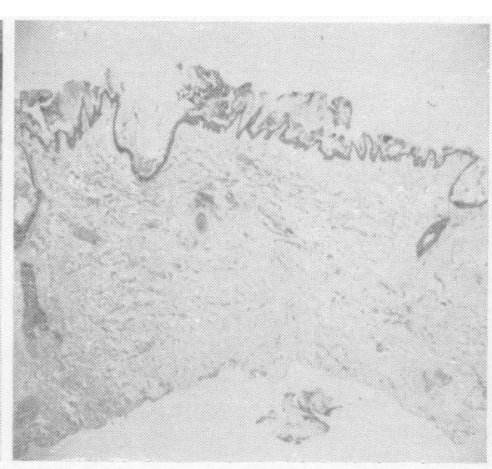

(b)

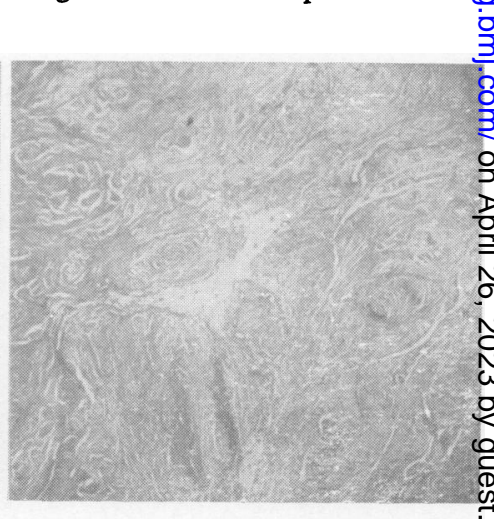

(c)

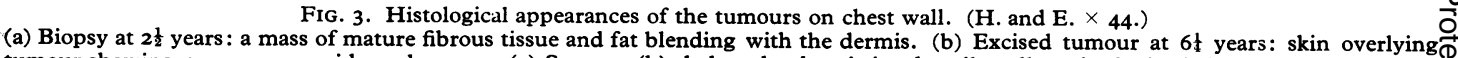
tumour showing a verrucous epidermal naevus. (c) Same as (b): below the dermis is a heavily collagenized whorled mass of fibrous tissueß surrounding a central island of adipose tissue which accounts for the bulk of the tumour. 
tion by Dr Pugh as being a subcutaneous fibrolipoma. His findings were that, 'both tissues are mature. The fibrous component is poorly cellular and heavily collagenised as it was in the previous biopsy. There is no infiltration of pectoral muscle fibres and the appearances are those of a hamartoma. The skin shows the appearances of a verrucous epidermal naevus. Melanin is present in the epidermis but is not excessive. The pigmentation of the skin is largely due to hyperkeratosis. Many micro-organisms are present in this keratin' (Fig. 3a and b).

\section{Discussion}

Many organs of the body can be affected in a variety of ways in epiloia, resulting in an extensive range of manifestations in addition to the diagnostically crucial findings of cerebral tuberous sclerosis and facial adenoma sebaceum. Some of the more unusual abnormalities noted in persons with the disease may be coincidental and not due to the irregularly dominant abnormal gene which is considered (Penrose, I963) to determine the manifestations of epiloia. In the present case, however, the tumours on the chest wall were quite consistent with the diagnosis of epiloia in that they were hamartomatous in nature and displayed overgrowth of fibrous tissue, well-recognized features in this disease. Nevertheless, the rapid growth and large size of these masses were exceptional, cutaneous tumours in epiloia seldom exceeding the dimensions of a walnut. The only record we were able to find of a case rather similar to the present one was by Nickel and Reed (I962) who briefly referred to the presence of a large 'fibromatous hamartoma' of the chest wall in an 18-yearold youth with tuberous sclerosis. These findings, though rare, provide a further example of the considerable variability that occurs in the symptomatology of epiloia.

\section{Summary}

Unusual tumours on the chest wall, in an otherwise typical case of epiloia, are reported, providing a further illustration of the protean nature of this genetically determined disease.

We thank Drs. A. White Franklin, R. Vacher, and K. Hugh-Jones, and Mr. R. S. Murley for kindly allowing us to make use of information gathered while the child discussed in this report was in their care. We are grateful also to Dr. J. I. Pugh who generously provided the histological reports and photomicrographs (Fig. 3) of the chest tumours, and to Miss M. Stokes for preparing these photomicrographs.

\section{REFERENCES}

Butterworth, T., and Wilson, McC., Jr. (194I). Dermatologic aspects of tuberous sclerosis. Arch. Derm. Syph. (Chic.), 43, I.

Nickel, W. R., and Reed, W. B. (1962). Tuberous sclerosis: special reference to the microscopic alterations in the cutaneous hamartomas. Arch. Derm., 85, 209.

Penrose, L. S. (1963). The Biology of Mental Defect, 3rd ed. Sidgwick and Jackson, London. 